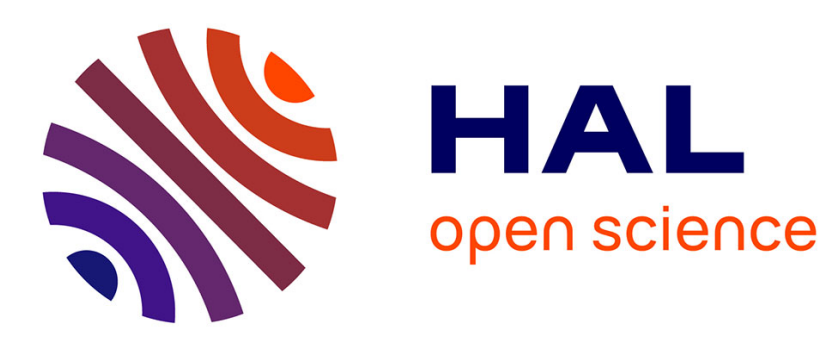

\title{
A probabilistic procedure to describe site amplification factors for seismic design codes
}

\author{
M. Abdullah Sandkkaya, Sinan Akkar, Pierre Yves Bard
}

\section{To cite this version:}

M. Abdullah Sandkkaya, Sinan Akkar, Pierre Yves Bard. A probabilistic procedure to describe site amplification factors for seismic design codes. Soil Dynamics and Earthquake Engineering, 2018, 10.1016/j.soildyn.2018.01.050 . insu-01741413

\section{HAL Id: insu-01741413 \\ https://hal-insu.archives-ouvertes.fr/insu-01741413}

Submitted on 31 May 2021

HAL is a multi-disciplinary open access archive for the deposit and dissemination of scientific research documents, whether they are published or not. The documents may come from teaching and research institutions in France or abroad, or from public or private research centers.
L'archive ouverte pluridisciplinaire HAL, est destinée au dépôt et à la diffusion de documents scientifiques de niveau recherche, publiés ou non, émanant des établissements d'enseignement et de recherche français ou étrangers, des laboratoires publics ou privés. 


\title{
A Probabilistic Procedure to Describe Site Amplification Factors for Seismic Design Codes
}

M. Abdullah Sandikkaya ${ }^{(a)}$, Sinan Akkar ${ }^{(b) *}$, and Pierre-Yves Bard ${ }^{(c)}$

(a) Hacettepe University, Department of Civil Engineering, Ankara, Turkey

(b) Kandilli Obs. Research Institute, Department of Earthquake Engineering, Istanbul, Turkey

(c) Université Grenoble-Alpes/CNRS/IRD/IFSTTAR, ISTerre, Grenoble, .France

* Corresponding Author: sinan.akkar@boun.edu.tr

\begin{abstract}
We introduce a site factor computation method for a region by extending the site-specific and probabilistic site amplification approach in Bazzuro and Cornell (2004). The site-factor exceedance probability is estimated from the exceedance probabilities of the reference rock ground motion and the soil amplification conditioned on the reference rock ground motion. The former probability is represented by regional hazard curves. The latter probability is computed from soil amplification models. The proposed method is capable of yielding site factors for a target exceedance probability. This property does not exist in the current code-based site factors. Given a site class, if the site factors and the reference rock spectrum possess the same exceedance probability the resulting spectrum would have the same probability of exceedance. The use of such probabilistically consistent earthquake demands would be more relevant for probability-based seismic design and assessment. Owing to the use of hazard curves, the proposed method can account for regional seismicity in the computation of site factors.
\end{abstract}

\section{Keywords}

Nonlinear soil amplification; hazard-consistent site factors; design codes; 


\section{Introduction and Background}

Site effect (or site amplification) is one of the essential components in seismic design. Site amplification was defined as the ratios of ground-motion intensity measures (GMIMs) at a soil site to their counterparts measured at a nearby rock site [1]. Since site amplification strongly depends on the site classification, these two topics evolved together during the last four decades. Seed et al. [2] showed the differences between four site conditions in terms of spectral shapes. Studies by Borcherdt [3] and Dobry et al. [4] led the formulation of site classification schemes with emphasis on soil nonlinearity. Their site classifications utilize either geological, geophysical or geotechnical parameters. The site classification as well as soil amplification is further investigated in many other papers [5-8]. The 2009 edition of NEHRP (National Earthquake Hazard Reduction Program) provisions [9] and Eurocode 8 [10] (EC8) used some of these studies (or other similar ones) to shape their site classification schemes as well as corresponding design spectra and site factors.

NEHRP provisions and EC8 use discrete $\mathrm{V}_{\mathrm{S} 30}$ intervals to classify different soil conditions. However, the way they compute site factors is different. The study by Borcherdt [3] that used the strong-motion recordings of the 1989 Loma Prieta, California earthquake established the principal methodology for the determination of NEHRP site factors. In essence, the NEHRP provisions describe the site factors as a function of reference rock pseudo-spectral accelerations $\left(\mathrm{PSA}_{\text {rock }}\right)$ at $\mathrm{T}=0.2 \mathrm{~s}$ and $\mathrm{T}=1.0 \mathrm{~s}$. The reference rock is characterized by $\mathrm{V}_{\mathrm{S} 30}=760 \mathrm{~m} / \mathrm{s}$ (referred to as $\mathrm{B} / \mathrm{C}$ site class boundary) and the site factors modify $\mathrm{PSA}_{\text {rock }}$ at $\mathrm{T}=0.2 \mathrm{~s}$ and $\mathrm{T}=1.0 \mathrm{~s}$ for different soil conditions. The NEHRP site factors attain values depending on the amplitudes of reference PSA ${ }_{\text {rock }}$ and they account for nonlinear soil behavior. The nonlinear soil behavior becomes prominent with decreasing soil stiffness (i.e., softer soil conditions) and when short-period spectral ordinates at reference rock attain large values. EC8 implements the Rey et al. [6] study and provides two sets of site factors for low and high seismicity regions. This code combines the site factors with site-class and seismic-region dependent spectral shapes (i.e., Type 1 vs. Type 2). The EC8 site factors disregard nonlinear soil behavior that generally results in higher spectral ordinates as site conditions change from rock to softer soils. An example violating this general trend is the lower site amplification of site class $\mathrm{C}$ $\left(1.15 ; 180 \mathrm{~m} / \mathrm{s} \leq \mathrm{V}_{\mathrm{S} 30}<360 \mathrm{~m} / \mathrm{s}\right)$ with respect to site class $\mathrm{B}\left(1.2 ; 360 \mathrm{~m} / \mathrm{s} \leq \mathrm{V}_{\mathrm{S} 30}<760 \mathrm{~m} / \mathrm{s}\right)$ in Type 1 (high seismicity) spectrum. 
Pitilakis et al. [11] have recently proposed a revision to the existing EC8 site factors by applying a logic tree approach composed of two branches. The first branch employs the Rey et al. [6] procedure and the second branch uses non-reference site approach proposed by Stewart et al. [7]. They kept the existing normalized spectral shapes recommended in EC8 and used a subset of a global strong-motion dataset [12] to refine the site factors for each site class and seismicity level. Their findings are systematically higher than the original EC8 site factors except for site class $\mathrm{D}\left(\mathrm{V}_{\mathrm{S} 30}<180 \mathrm{~m} / \mathrm{s}\right)$ where they propose site specific response analysis. The site factors computed by Pitilakis et al. [11] do not explicitly consider soil nonlinearity and they tend to yield conservative shortperiod spectral ordinates at soft sites with respect to soil amplifications obtained from nonlinear site models [13].

Huang et al. [14] and Borcherdt [15] used the GMPEs developed under NGA-West1 project [16] to study the properness of NEHRP site factors. Huang et al. [14] considered a set of fictitious reverse and strike-slip scenarios with $5 \leq \mathrm{M}_{\mathrm{w}} \leq 8$ and source-to-site distances less than $50 \mathrm{~km}$. They computed site factors for a range of $\mathrm{V}_{\mathrm{S} 30}$ values varying between $150 \mathrm{~m} / \mathrm{s}$ and $1500 \mathrm{~m} / \mathrm{s}$ by normalizing the estimated spectral ordinates with those of reference rock site of $\mathrm{V}_{\mathrm{S} 30}=760 \mathrm{~m} / \mathrm{s}$. The site factors by Huang et al. [14] depict lesser soil nonlinearity with respect to those given in NEHRP for short-period spectral ordinates (i.e., lesser reduction in short-period spectral ordinates at soft sites). Their comparisons also suggest larger spectral amplifications than those in NEHRP for longer spectral periods. The statistical study by Borcherdt [15] considered $\mathrm{V}_{\mathrm{S} 30}=1050 \mathrm{~m} / \mathrm{s}$ for the reference rock site. His conclusions on NEHRP site factors are similar to Huang et al. [14]. The NEHRP site factors were evaluated independently by Seyhan and Stewart [17] via their semi-empirical nonlinear site model that is developed under NGA-West2 project [18]. The Seyhan and Stewart [17] site factors also yield lesser soil nonlinearity at short spectral periods. Contrary to the results summarized above, the nonlinear site model by Sandıkkaya et al. [13] suggests slightly higher soil nonlinearity with respect to the 2009 NEHRP site factors for short-period, large amplitude spectral ordinates at reference rock.

The discussions summarizing the literature in the above paragraphs indicate a variety of site models and approaches that yield different results for site factors. This fact brings forward the importance of epistemic (modeling) uncertainty in the determination of site factors that may have serious implications in the computation of earthquake induced seismic design forces. The 2015 edition of NEHRP provisions [19] have already adopted the findings of Seyhan and Stewart [17] as new site factors. The Seyhan and Stewart [17] site factors are also used in the seismic design load definitions by ASCE/SEI 7-16 [20]. 
We believe that EC8 will soon consider the outcomes of these new studies to assess the coherency and consistency of its current site factors.

This paper presents a probabilistic methodology to compute site factors for seismic design codes. We first evaluate the site factors that are currently provided in EC8 and 2015 edition of NEHRP by implementing a procedure similar to Huang et al. [14]. The observed trends from this step refined our understanding about the behavior of site factors to propose our methodology. The presented methodology uses the probability distributions of reference rock hazard and site models to compute site factors having a specific exceedance probability. This approach has already been implemented to the sitespecific probabilistic site amplification [21] but we applied it for an extended region with some suggested modifications. The probabilistic seismic hazard maps of USGS [22] are used to present case studies to discuss the merits of the proposed procedure for regional probabilistic site factors having consistent exceedance probabilities with the reference rock ground motion. We presented case studies for regional site factors by using the proposed methodology to demonstrate its sensitivity to regional seismicity. The case studies also consider another probability-based site factor method with a different underlying theory to highlight how different soil amplification models and probabilistic methodologies impact the computed site factors. We believe that the proposed procedure provides strong grounds to compute hazard-consistent site factors for the future updates of seismic design codes by making use of readily available regional reference rock PSHA results (e.g., Seismic Hazard Harmonization in Europe, SHARE [23] or [22; 24]).

\section{Evaluation of in-practice site factors}

The current state-of-practice in site amplification studies is to develop empirical (or semi-empirical / theoretical) models that are continuous functions of $\mathrm{V}_{\mathrm{S} 30}$ as well as $\mathrm{PGA}_{\text {rock }}$ or PSA $\mathrm{P}_{\text {rock }}$ (peak ground acceleration or pseudo spectral acceleration at reference rock) for describing linear and nonlinear soil behavior [13;17;25-28] $]^{1}$. In order to understand the implications of current practice, we use the site models by Seyhan and Stewart [17] (SS14), Walling et al. [27] $\left(\mathrm{WAS}^{2}{ }^{2}\right.$ ), Chiou and Youngs ${ }^{3}$ [29] (CY14) and

\footnotetext{
${ }^{1}$ To the best knowledge of authors Abrahamson and Silva [25] is the pioneer GMPE to account for soil nonlinearity. Older GMPEs as well as some current ones disregard soil nonlinearity because the site information in their strong-motion databases do not contain sufficient information to characterize the nonlinear site features. On the other hand, some GMPEs simply disregard soil nonlinearity for groundmotion modeling aspects.

${ }^{2}$ WAS08 provide only nonlinear site coefficients and the linear site coefficients are computed in the CB14 study.
} 
Sandikkaya et al. [13] (SAB13) to assess the magnitude and distance dependency on site factors. SS14, WAS08 and CY14 are developed under the framework of NGA projects and are used in Boore et al. [30] (BSSA14). Campbell and Bozorgnia [31] (CB14) and Chiou and Youngs [29] GMPEs describe the site effects on the estimated GMIMs by the built-in site functions in their predictive models. SAB13 is one of the products of SHARE project and is used in the functional form of Akkar et al. [32] (ASB14) ground-motion model. The reader is referred to the original publications for detailed descriptions of the models.

The use of four models enabled us to assess the aleatory and epistemic uncertainty in the computation of site factors. We first generated a suite of magnitude-distance pairs and estimated the corresponding reference rock PGA values $\left(\mathrm{PGA}_{\text {rock }}\right)$ for a range of epsilon values $(\varepsilon$; number of standard deviations above or below the median ground-motion estimation) by using BSSA14, CB14, CY14 and ASB14. These GMPEs employ the site models of interest as explained in the previous paragraph. The reference rock site is described by $\mathrm{V}_{\mathrm{S} 30}=760 \mathrm{~m} / \mathrm{s}$ in the analyses. The style-of-faulting is strike-slip in all scenarios with a dip angle of 90 degrees and source-to-site distance metric used by each GMPE is computed accordingly. The epsilon range is taken between \pm 2 with 0.25 unit increments to simulate the aleatory variability in reference rock GMIMs. The magnitude and distance ranges vary between $4 \leq M_{w} \leq 8$ and $R_{J B} \leq 200 \mathrm{~km}$, respectively. The magnitude increments are chosen as 0.2 units whereas, given the power law dependence of distance, the distance increment is increased with logarithmic distance intervals $(0.2$ $\log$ units for $\mathrm{R}_{\mathrm{JB}}<50 \mathrm{~km}$ and 0.1 log-units at larger distances). This effort yielded a large sample size for each $\mathrm{PGA}_{\text {rock }}$ level to observe the behavior of site amplification.

We selected two target PGA rock levels: 0.1g (low seismic activity and demand - Type 2 spectrum in EC8) and 0.5g (high seismic activity and demand - Type 1 spectrum in EC8) for studying the trends in linear and nonlinear site effects. The magnitude-distanceepsilon triplets that yield $\mathrm{PGA}_{\text {rock }}$ values within $\pm 10 \%$ of the target $\mathrm{PGA}_{\text {rock }}$ level (i.e., either $0.1 \mathrm{~g}$ or $0.5 \mathrm{~g}$ ) were binned in the same group. Figure 1 illustrates the binned magnitude-distance-epsilon distributions of $0.1 \mathrm{~g}$ and $0.5 \mathrm{~g}$ for ASB14 as an example. The magnitude-distance scatters of target PGA $_{\text {rock }}$ levels for other GMPEs show comparable patterns with the ones given in this figure. Figure 1 also shows the variation of magnitude-distance sets of ASB14 for different epsilon intervals. As depicted in Figure 1, this step yields a large sample size of triplets for each PGA $\mathrm{A}_{\text {rock }}$ level.

\footnotetext{
${ }^{3}$ The CY14 site model is produced during the ground motion model development.
} 
For periods up to $4.0 \mathrm{~s}$ and using the site model corresponding to relevant triplet database (such as using SAB13 site model together with the triplets produced from ASB14), we computed the site amplifications of each triplet for $V_{S 30}$ values of $1050 \mathrm{~m} / \mathrm{s}$ (rock site condition of NEHRP B or EC8 A), 760m/s (a proxy for NEHRP B/C or approximately EC8 A/B boundaries), 525m/s (stiff soil representing NEHRP C or EC8 B), $255 \mathrm{~m} / \mathrm{s}$ (soft soil class corresponding to NEHRP D or EC8 C) and $150 \mathrm{~m} / \mathrm{s}$ (very soft soil condition defined as NEHRP E or EC8 D). The site amplification factors corresponding to each triplet were computed by normalizing the site amplifications of $\mathrm{V}_{\mathrm{S} 30}=1050 \mathrm{~m} / \mathrm{s}, 525 \mathrm{~m} / \mathrm{s}, 255 \mathrm{~m} / \mathrm{s}$ and $150 \mathrm{~m} / \mathrm{s}$ with their counterparts computed at $\mathrm{V}_{\mathrm{S} 30}=760 \mathrm{~m} / \mathrm{s}$.

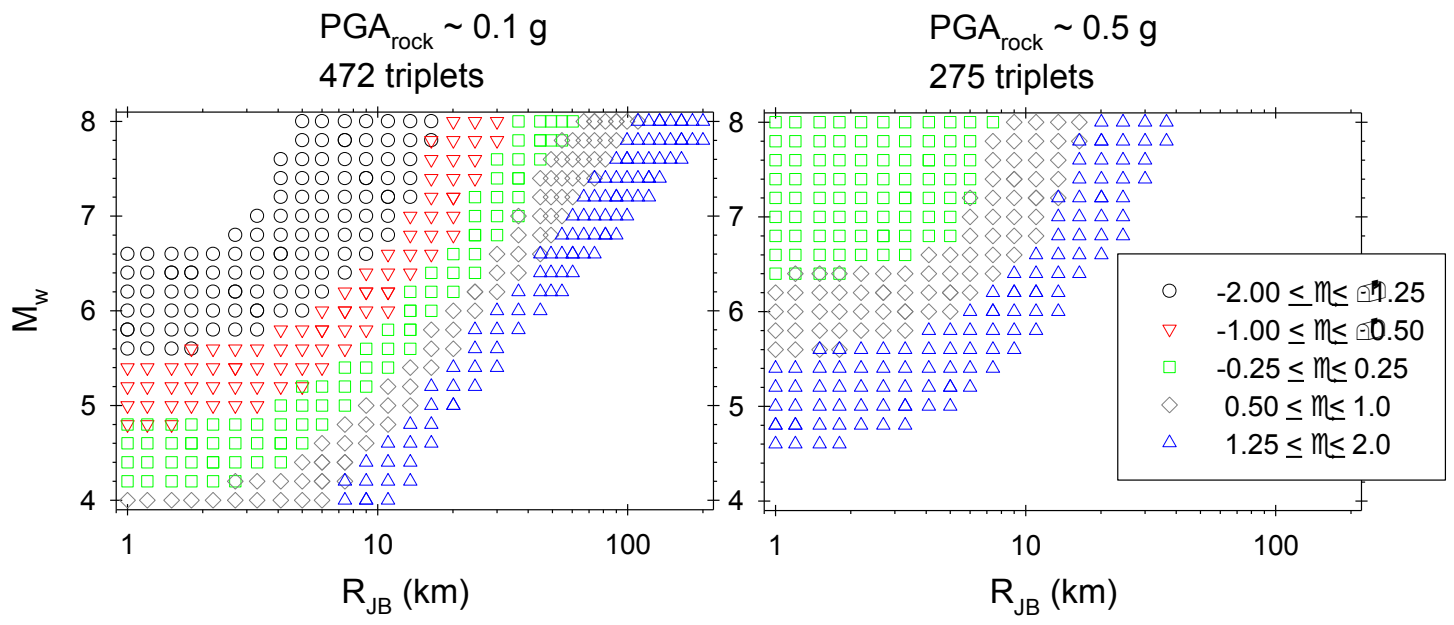

Fig. 1. $\mathrm{M}_{\mathrm{W}}-\mathrm{R}_{\mathrm{JB}}-\varepsilon$ scatters for two $\mathrm{PGA}_{\text {rock }}$ levels that are used in the triplet approach. The given distributions are specific to ASB14. The number of triplets for each PGA $_{\text {rock }}$ bin are indicated on the plots.

Figure 2 shows the period-dependent behavior of median site amplifications from the triplet approach. The ranges of site amplifications from triplets (grey shaded areas) as well as the site amplifications of the 2015 edition of NEHRP and EC8 provisions are also shown in Figure 2. The NEHRP ${ }^{4}$ and EC8 site factors shown in Figure 2 implicitly consider the effects of site-class dependent spectral shapes on the site factors. Since EC8 anchors the spectral demands to PGA, we can make a direct comparison between our

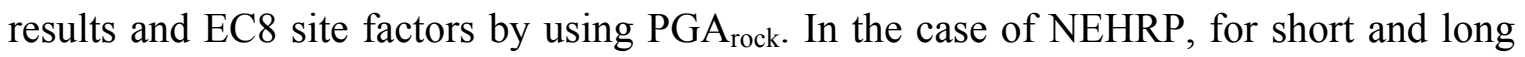
periods, the rock spectral intensities are adjusted with a factor of 2.3 and 0.7 , respectively and linear interpolation is done to mimic the pre-defined NEHRP values [17]. The first and second column panels in Figure 2 display the site factors for $\mathrm{PGA}_{\text {rock }}=0.1 \mathrm{~g}$ and $\mathrm{PGA}_{\text {rock }}=0.5 \mathrm{~g}$, respectively. The site factors from first row to last row in Figure 2

\footnotetext{
${ }^{4}$ Whenever NEHRP recommends the implementation of site-specific ground motion procedure, we use the site factors provided by SS14.
} 
correspond to $\mathrm{V}_{\mathrm{S} 30}=1050 \mathrm{~m} / \mathrm{s}, 525 \mathrm{~m} / \mathrm{s}$ and $255 \mathrm{~m} / \mathrm{s}$, and $150 \mathrm{~m} / \mathrm{s}$, respectively. We used Type $1 \mathrm{EC} 8$ site factors for $\mathrm{PGA}_{\text {rock }}=0.5 \mathrm{~g}$ and Type 2 site factors for $\mathrm{PGA}_{\text {rock }}=0.1 \mathrm{~g}$.
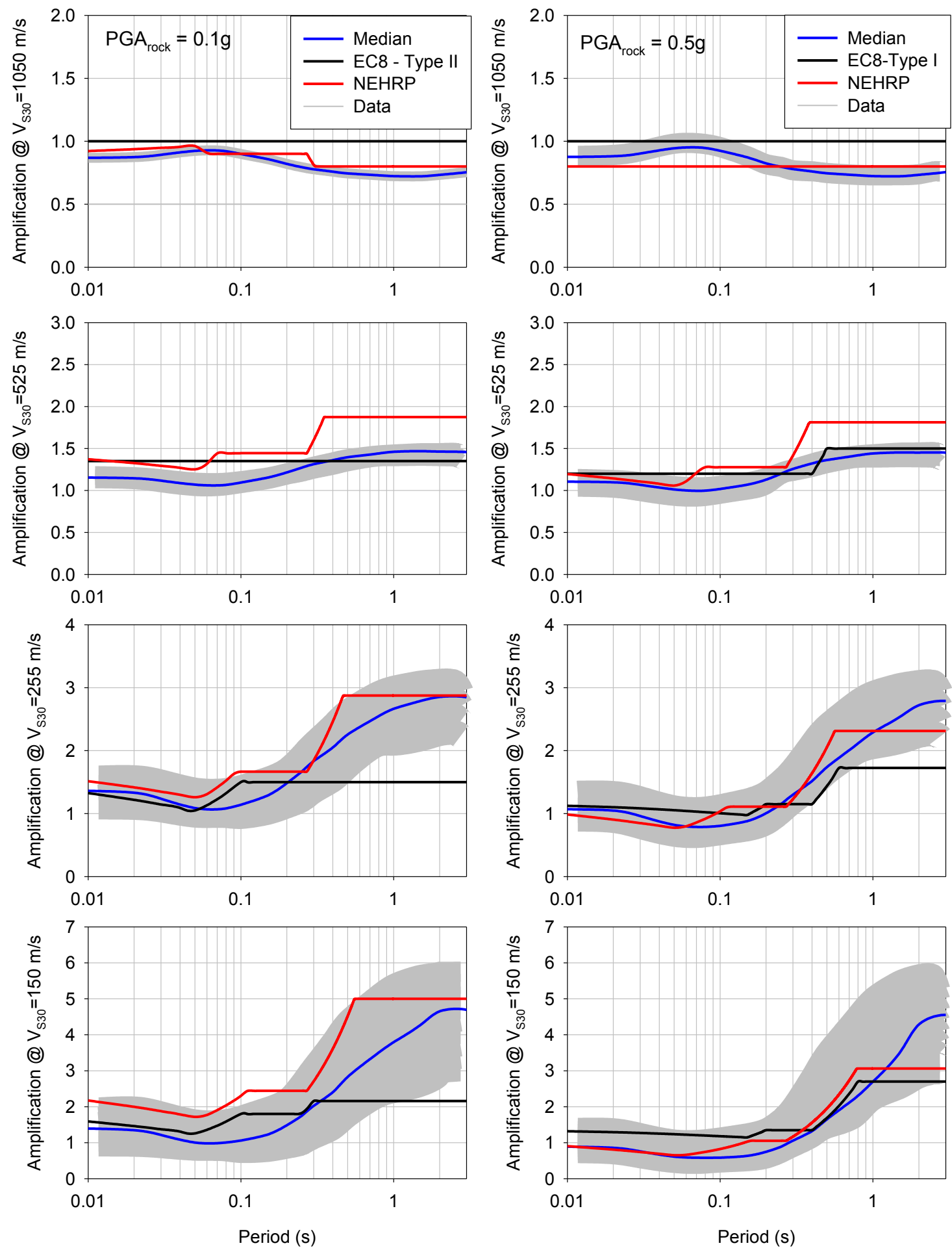

Fig. 2. Period-dependent site amplification factors for different $\mathrm{V}_{\mathrm{S} 30}$ and $\mathrm{PGA}_{\text {rock }}$ that are computed from triplets (grey shaded area), corresponding median trends (blue lines) and their comparisons with EC8 (black line) and NEHRP (red line).

The panels in Figure 2 suggest that the trends in short-period $(\mathrm{T}<0.5 \mathrm{~s})$ and longperiod $(\mathrm{T}>1.0 \mathrm{~s})$ amplifications differ from each other. This difference becomes more prominent at soft $\left(\mathrm{V}_{\mathrm{S} 30}=255 \mathrm{~m} / \mathrm{s}\right)$ and very soft sites $\left(\mathrm{V}_{\mathrm{S} 30}=150 \mathrm{~m} / \mathrm{s}\right)$. For rock sites $\left(\mathrm{V}_{\mathrm{S} 30}\right.$ 
$=1050 \mathrm{~m} / \mathrm{s}$ ), the NEHRP and triplet amplifications are similar to each other whereas EC8 yields conservative results with respect to other two. The NEHRP site amplifications of stiff soil $\left(\mathrm{V}_{\mathrm{S} 30}=525 \mathrm{~m} / \mathrm{s}\right)$ overshoot the triplet amplifications at low $\mathrm{PGA}_{\text {rock}}$. They follow triplet amplifications for periods up to $\mathrm{T}=0.3 \mathrm{~s}$ and then suggest larger site amplifications with respect to triplets in the rest of the spectral periods. The stiff soil EC8 amplifications are comparable to the triplets for $\mathrm{PGA}_{\text {rock }}=0.5 \mathrm{~g}$ whereas their similarity with the triplet

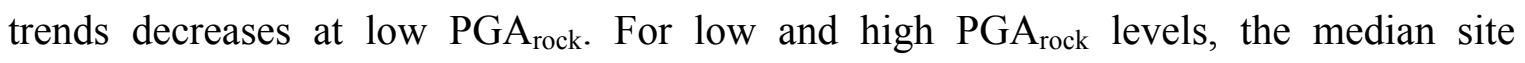
amplifications of triplets and NEHRP yield fairly similar trends at $\mathrm{V}_{\mathrm{S} 30}=255 \mathrm{~m} / \mathrm{s}$. The EC8 amplifications behave similarly with the other two approaches at very short and short periods but they suggest considerably lower amplifications with respect to triplets and NEHRP site amplifications as spectral periods become longer. Site amplification observations for very soft sites $\left(\mathrm{V}_{\mathrm{S} 30}=150 \mathrm{~m} / \mathrm{s}\right)$ show similarities with those of soft sites $\left(\mathrm{V}_{\mathrm{S} 30}=255 \mathrm{~m} / \mathrm{s}\right)$. This time the discrepancy between EC8 site amplification and triplets

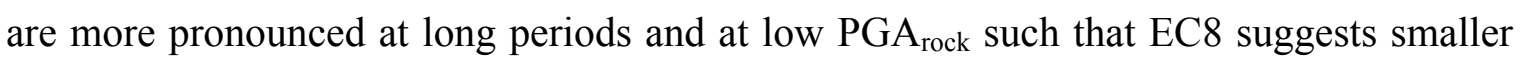
site amplification with respect to the triplets. For very soft site conditions, the NEHRP and triplet site amplifications agree fairly well at short periods for high PGA $_{\text {rock }}$ but as spectral periods shift towards longer period range the triplets yield larger spectral amplitudes with respect to NEHRP at this PGA $_{\text {rock }}$ level. The NEHRP site amplifications are larger than those computed from triplets at low PGA $_{\text {rock }}$ for this soil class. Our comparisons between NEHRP and triplet soil amplifications carry some similarities with Huang et al. [14] and Borcherdt [15] at the long period range for soft and very soft soils. They differ with respect to these two studies at short periods and for high PGA $_{\text {rock }}$ (where soil nonlinearity is supposed to be more pronounced) because the NEHRP and triplet site amplifications follow each other closely in our case.

The above exercise is repeated for $\mathrm{PGA}_{\text {rock }}=0.3 \mathrm{~g}$ since $0.5 \mathrm{~g}$, as the upper reference rock PGA in the above example, can be the representative of a rare earthquake scenario, for Northern and Central parts of Europe. The site is characterized by $V_{\mathrm{S} 30}=255 \mathrm{~m} / \mathrm{s}$ that invoked nonlinear soil response for $\mathrm{PGA}_{\text {rock }}=0.5 \mathrm{~g}$ in the previous example. The shortperiod (even towards intermediate periods - e.g., $\mathrm{T}=1 \mathrm{~s}$ ) median site amplifications depicted in Figure 3 suggest a fairly better performance of EC8 site factors (all three curves follow each other closely) at this PGA $_{\text {rock }}$ level. However, both EC8 and NEHRP site amplifications fall below the triplet median, which is also observed in the previous example. Despite the observations made from this case study, one should note that PGA $_{\text {rock }}$ levels can exceed $0.3 \mathrm{~g}$ in particular towards larger return periods such as $T_{R}=$ 
2475 years; a target return period that is frequently used in assessing the structural performance of existing structural systems.

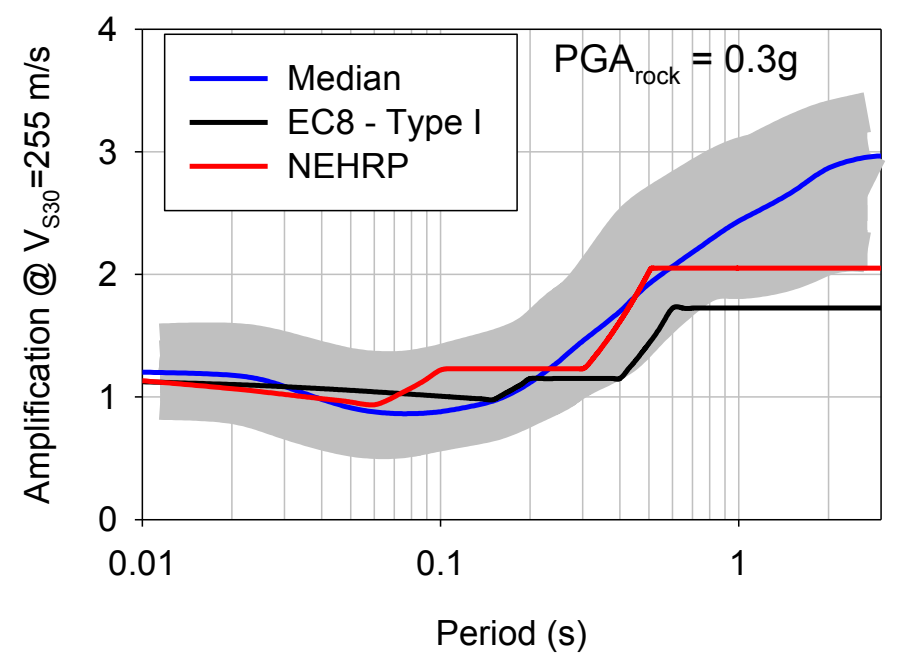

Fig. 3. Variation of site amplification factors from triplet analyses and comparison of median amplitudes with NEHRP and EC8 site amplifications. (Presentation and computation methodology is the same as in Figure 2 but only for $V_{S 30}=255 \mathrm{~m} / \mathrm{s}$ and $\mathrm{PGA}_{\text {rock }}=0.3 \mathrm{~g}$ ).

The overall results in these case studies underline an increasing discrepancy between the triplet and EC8 site amplifications for low-velocity site classes (represented by $\mathrm{V}_{\mathrm{S} 30}=$ $255 \mathrm{~m} / \mathrm{s}$ and $\mathrm{V}_{\mathrm{S} 30}=150 \mathrm{~m} / \mathrm{s}$ in the comparative case study) and high $\mathrm{PGA}_{\text {rock }}$ (i.e. $\mathrm{PGA}_{\text {rock }}$ $\geq 0.3 \mathrm{~g}$ ). A mismatch between the spectral amplifications of triplets and NEHRP provisions is also observed but they are generally within the tolerance limits except for long-period stiff site conditions. The discrepancies in site amplification for soft and very soft soil conditions in EC8 exist for the entire period range, in particular for high $\mathrm{PGA}_{\text {rock }}$ (e.g., PGA $_{\text {rock }}=0.5 \mathrm{~g}$ ), but they are more notable at longer spectral periods. The poorly constrained nonlinear soil behavior in EC8 as well as its outdated PGA-anchored spectral shape that fails to capture the actual spectral trends in the long periods can be the main sources behind these observations. Needless to say, the assumptions we made in binning the triplets for the selected reference PGA values may prevent a fully unbiased assessment of EC8 spectral amplifications. Nevertheless our observations from the limited triplet case studies still call for the importance of proper definition of soil nonlinearity as well as period-dependent site factors that seem to be poorly constrained in the current EC8 provisions.

Figure 4 compares the code-based soft and very soft soil site factors $\left(\mathrm{V}_{\mathrm{S} 30}=255 \mathrm{~m} / \mathrm{s}\right.$ and $\mathrm{V}_{\mathrm{S} 30}=150 \mathrm{~m} / \mathrm{s}$, respectively) by assuming log-normal distribution for the triplet site amplifications. The log-normally distributed triplet site factors are computed by using the 
Borcherdt [3] method that averages the site amplifications between $0.1 \mathrm{~s} \leq \mathrm{T} \leq 0.5 \mathrm{~s}$ and $0.4 \mathrm{~s} \leq \mathrm{T} \leq 2.0 \mathrm{~s}$ to represent the short-period $(\mathrm{T}=0.2 \mathrm{~s})$ and $\mathrm{T}=1 \mathrm{~s}$ site factors, respectively. The cumulative log-normal soft soil $\left(\mathrm{V}_{\mathrm{S} 30}=255 \mathrm{~m} / \mathrm{s}\right)$ site factor distributions from triplets are compared with EC8 C and NEHRP D site factors at the top row of Figure 4. The bottom row in this figure compares the log-normal distributions of very soft soil $\left(\mathrm{V}_{\mathrm{S} 30}=150 \mathrm{~m} / \mathrm{s}\right)$ triplet site factors with EC8 D and NEHRP E site amplifications. The NEHRP D and E (soft and very soft soil, respectively) site factors at $T=0.2 \mathrm{~s}$ are computed from PSA $\mathrm{T}_{\mathrm{T}=0.2 \mathrm{~s}}=0.23 \mathrm{~g}$ and $\mathrm{PSA}_{\mathrm{T}=0.2 \mathrm{~s}}=1.15 \mathrm{~g}$ at reference rock that correspond

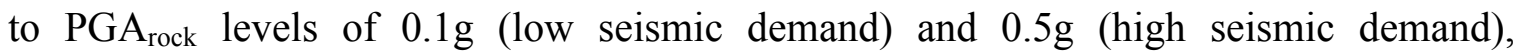
respectively. In a similar fashion, $\mathrm{T}=1.0 \mathrm{~s}$ NEHRP site factors are computed from $\mathrm{PSA}_{\mathrm{T}=1.0 \mathrm{~s}}=0.07 \mathrm{~g}$ and $\mathrm{PSA}_{\mathrm{T}=1.0 \mathrm{~s}}=0.35 \mathrm{~g}$ representing $0.1 \mathrm{~g}$ and $0.5 \mathrm{~g}$ of $\mathrm{PGA}_{\text {rock }}$ levels, respectively. The designated $\mathrm{T}=0.2 \mathrm{~s}$ and $\mathrm{T}=1.0 \mathrm{~s}$ spectral accelerations are the logarithmic means of the triplets binned for $\mathrm{PGA}_{\text {rock }}=0.1 \mathrm{~g}$ and $\mathrm{PGA}_{\text {rock }}=0.5 \mathrm{~g}$. No such calculations are necessary for the EC8 site factors $\left(\mathrm{EC} 8 \mathrm{C}\right.$ and $\mathrm{D}$ site classes for $\mathrm{V}_{\mathrm{S} 30}=$ $255 \mathrm{~m} / \mathrm{s}$ and $\mathrm{V}_{\mathrm{S} 30}=150 \mathrm{~m} / \mathrm{s}$, respectively) because site factors in EC8 are single-valued constants that are independent of a spectral period range.

The comparative plots indicate that NEHRP site factors tend to be more conservative (pose small exceedance probabilities) at low seismic demands and softer site conditions. The NEHRP short-period and $\mathrm{T}=1.0 \mathrm{~s}$ site factors at very soft sites under high seismic demands are closer to the median site factors of triplets. On the other hand, the median triplet site factors are larger than the NEHRP short-period and $\mathrm{T}=1.0 \mathrm{~s}$ site factors for soft sites $\left(\mathrm{V}_{\mathrm{S} 30}=255 \mathrm{~m} / \mathrm{s}\right)$ for both low and high seismic demands. The NEHRP shortperiod and $\mathrm{T}=1.0 \mathrm{~s}$ site factors are larger than the corresponding triplet site factors at very soft sites $\left(\mathrm{V}_{\mathrm{S} 30}=150 \mathrm{~m} / \mathrm{s}\right)$ when seismic demands are low. The EC8 site factors suggest very low site amplifications for $\mathrm{T}=1.0 \mathrm{~s}$ for both soft and very soft sites independent of the seismic demand level. The short-period EC8 site amplifications are less conservative with respect to triplets for both low and high seismicity conditions. This trend changes for very soft sites and EC8 provides very conservative spectral amplifications with respect to triplets at high seismic demands. These observations may give an indication about the level of sensitivity in site factors to the variations in seismic activity.

Another interesting observation from Figure 4 is that the code-based site factors do not provide uniform (or homogenous) exceedance (or non-exceedance) probabilities for a given level of seismic demand. In other words, for a certain level of seismic activity (represented as either low or high seismic activity in this paper) the proposed code-based 
site factors can be either conservative or non-conservative in terms of exceedance probabilities provided that site factors follow a certain probability distribution.
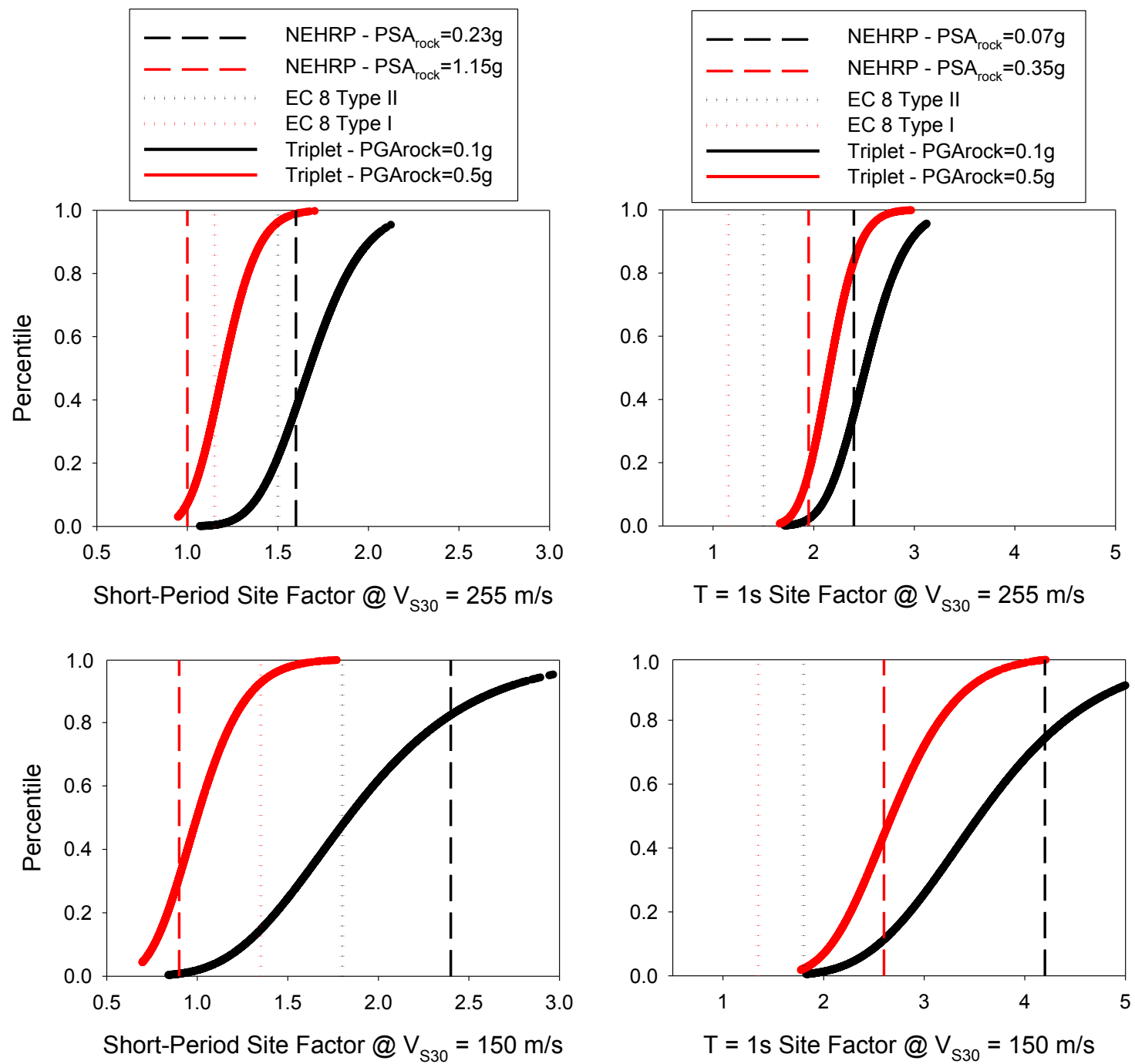

Fig. 4. Comparisons of triplet-based log-normal short-period $(\mathrm{T}=0.2 \mathrm{~s})$ and $\mathrm{T}=1.0 \mathrm{~s}$ site factor distributions for soft and very soft soils with EC8 and NEHRP provisions

\section{Proposed approach: probabilistic integration of earthquake occurrence and site amplification for code-based site factors}

The discussions in the previous section give useful insight about the implications of site factors in EC8 and NEHRP. They illustrate the effects of period dependence and soil nonlinearity on site factors at different ground motion levels (represented by PGA $_{\text {rock }}$ ). The triplet analyses also indicate the lack of uniformity in the exceedance probabilities of EC8 and NEHRP site factors under different soil conditions, seismic activity and spectral period intervals. 
In fact, site factors can be computed for a certain exceedance probability as in the case of uniform hazard spectrum. Such an approach combines the soil behavior and the seismic hazard curves used in the computation of hazard-consistent design spectrum (e.g., shortperiod and $\mathrm{T}=1.0 \mathrm{~s}$ spectral ordinates in NEHRP). The site amplifications computed from this approach are called as hazard-consistent site factors. They are more appropriate for probability-based performance-based seismic design since the engineer has a clear vision on the exceedance probabilities of site factors to assess their suitability for specific design objective. This approach is discussed further in the following.

There are several ways to compute hazard-consistent site amplifications. One can run PSHA using GMPEs that can properly model the soil behavior (linear/nonlinear soil response) for a specific or multiple site conditions [33]. The site amplifications relative to a reference rock condition computed from this approach would be hazard-consistent because they will represent a specific hazard level (a particular mean annual exceedance rate or return period) determined from PSHA. This procedure uses probabilistic seismic hazard concept and the resulting site amplifications rely on probabilistic concepts. Alternatively, one can use another probabilistic approach that convolves the exceedance probabilities of uniform hazard spectral ordinates at reference rock with a site specific soil amplification function developed from soil response analysis [21;34]. The soil amplification function (model) follows a probability distribution conditioned on reference rock spectral ordinate $\left(\mathrm{PGA}_{\text {rock }}\right.$ or $\left.\mathrm{PSA}_{\text {rock }}\right)$. Equation 1 shows the annual exceedance rate of a spectral ordinate, PSA(T), specific to a particular site condition under this method.

$$
\lambda(P S A(T)>y)=\int P\left(S A(T)>\frac{y}{x} \mid G M I M_{\text {rock }}=x\right) \mid d \lambda\left(G M I M_{\text {rock }}>x \mid\right.
$$

Here, $\lambda(\operatorname{PSA}(\mathrm{T})>\mathrm{y})$ denotes the annual frequency of PSA(T) exceeding a threshold $\mathrm{y}$ given a specific site condition. The first term on the right-hand side is the complimentary site amplification probability distribution conditioned on the reference rock ground motion intensity measure, GMIM rock $\left(\mathrm{PGA}_{\text {rock }}\right.$ or $\left.\mathrm{PSA}_{\text {rock }}\right)$. It is the probability of PSA(T) exceeding the threshold y when site amplification, SA, takes on some value greater than $\mathrm{y} / \mathrm{x}$ given that $\mathrm{GMIM}_{\text {rock }}=\mathrm{x}$. The second probability term is the derivative of $\mathrm{GMIM}_{\text {rock }}$ hazard curve that gives the probability of GMIM $_{\text {rock }}$ exceeding x. Bazzuro and Cornell [21] develop $P\left(S A(T)>y / x \mid G M I M_{\text {rock }}=x\right)$ from soil response analysis that is specific to a single site. Note that the hazard-consistent and full-probabilistic site amplification is the normalized $\lambda(P S A(T)>y)$ by $\lambda\left(P S A_{\text {rock }}(T)>y\right)$ at reference rock conditions.

We implement Equation (1), proposed procedure, to compute probabilistic site amplification factors together with the site models proposed in the literature (e.g., SS14, 
CB14, CY14 and SAB13). Site models such as those listed above are conditional probability distributions under a set of estimator parameters. Hence, they can be used in the first probability term on the right hand side of Equation (1). As we aim to use generic rock probabilistic seismic hazard maps of a region (e.g., a country) to compute site factors for seismic codes, the use of site models rather than the site-specific soil response is more convenient because the former would describe the specific character of a single site (or limited number of sites). The probabilistic site factors computed from this method represent a certain exceedance probability and would constitute an integral point for moving towards more realistic probability-based seismic design and performance assessment.

We note that the probabilistic approaches discussed in this section handle the site influence on GMIM in different ways. The conventional PSHA approach plugs the sitespecific $\mathrm{V}_{\mathrm{S} 30}$ into the GMPE and accounts for the aleatory variability in site response by integrating the hazard integral for a range of sigma ( $\sigma$; usually within $\pm 3 \sigma$ range). Here, sigma is the total standard deviation associated with the GMPE that generally measures the aleatory variability as the cumulative effects of source, radiation pattern and site. This is because very few GMPEs consider nonlinear soil response as a separate component of aleatory variability. (To the best of our knowledge some GMPEs developed under the framework of NGA-West1 [35] and NGA-West 2 [36] account for nonlinear soil response in their standard deviation). The proposed procedure that is inspired from Bazzuro and Cornell [21] considers the aleatory variability in site amplification through the standard deviation of the site model (soil amplification function). The epistemic uncertainty is considered by using multiple GMPEs (in the conventional PSHA approach) or multiple site amplification functions (in the proposed procedure). The following section explains the specific features of our procedure through a detailed case study. It then describes the implementation of our procedure to regional scale.

\subsection{Example case study}

To illustrate our hazard-consistent site factor methodology, we considered two specific regions in the western US. These regions are located in southern California and western Arizona. The central coordinates of the selected regions are $35.0^{\circ} \mathrm{N}-120.0^{\circ} \mathrm{W}$ (southern California) and $35.0^{\circ} \mathrm{N}-113.0^{\circ} \mathrm{W}$ (western Arizona). We mesh gridded 25 sites

for each region that are distributed regularly over a 0.2 degrees (Figure 5). The reason for 
choosing this case study from the US territory is the availability of seismic hazard inventory for the entire country at different return periods. We used the USGS Hazard Tool (https://earthquake.usgs.gov/hazards/interactive/) that employs the U.S. national probabilistic seismic hazard maps [22] although the aforementioned hazard maps are updated in 2014 [24]. The considered regions represent different levels of seismic activity and seismic sources: the location in southern California is dominated by moderate-tolarge size earthquakes that mainly occur on well-known faults whereas the region in western Arizona has a low-to-moderate seismic activity, which is attributed to background events (earthquakes that cannot be associated with faults).

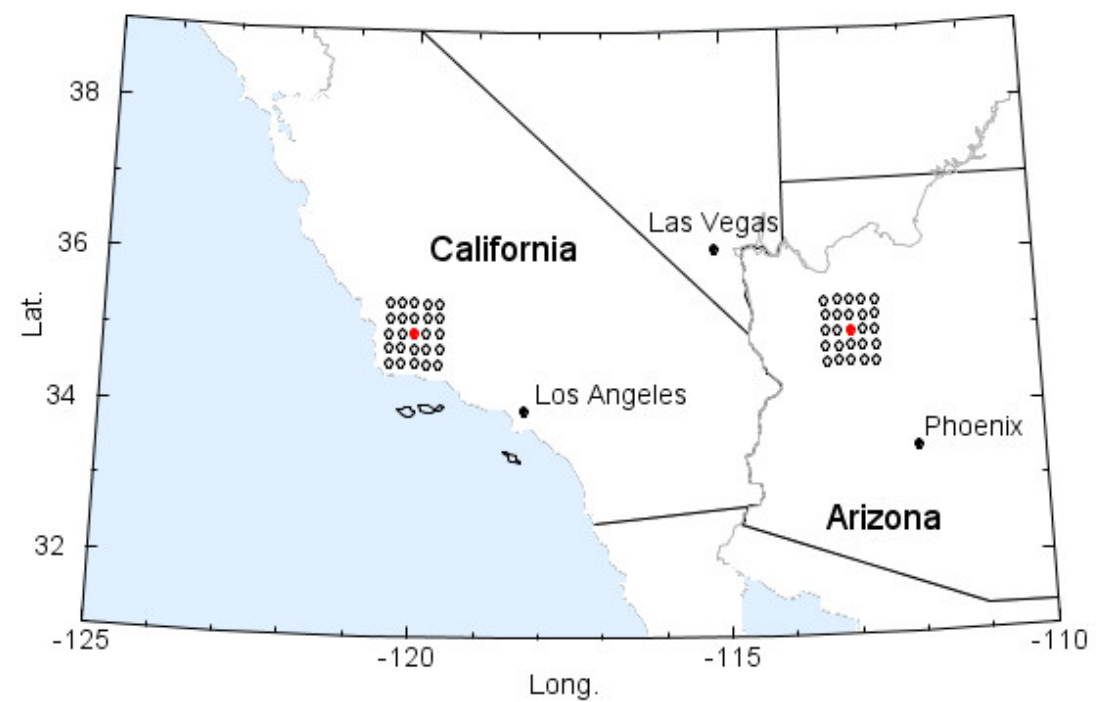

Fig. 5. The selected regions in southern California and western Arizona. Dots in each region are the sites distributed over a mesh with 0.2 degrees. The central site of each region is shown in red color.

\subsection{Discussions on the probabilistic site factors considering a specific site}

We first focus on the central site of the region selected in the southern California to illustrate the proposed procedure. Figures 6.a and 6.b demonstrate the hazard curves obtained from the two alternative probabilistic site factor methods at $\mathrm{T}=0.2 \mathrm{~s}$ and $\mathrm{T}=1.0 \mathrm{~s}$ for a site condition represented by $\mathrm{V}_{\mathrm{S} 30}=260 \mathrm{~m} / \mathrm{s}$. We choose this specific $\mathrm{V}_{\mathrm{S} 30}$ because our comparative plots also consider the probabilistic site factors computed from the sitespecific soil amplification model developed for this average shear-wave velocity in Bazzuro and Cornell [21]. This way, we not only address the significance of different probabilistic methods in site amplification computation but also focus on the sensitivity of site amplification results to different soil amplification models. 
The USGS generic rock $\left(\mathrm{V}_{\mathrm{S} 30}=760 \mathrm{~m} / \mathrm{s}\right)$ hazard curves at $\mathrm{T}=0.2 \mathrm{~s}($ Figure $6 . \mathrm{a})$ and $\mathrm{T}$ $=1.0 \mathrm{~s}$ (Figure 6.b) are used to calculate the hazard curves at $\mathrm{V}_{\mathrm{S} 30}=260 \mathrm{~m} / \mathrm{s}$ by applying (a) the Bazzuro and Cornell [21] site-specific soil amplification model (Alternative A), (b) the SAB13, SS14, CB14 and CY14 site models (Alternative B), and (c) the PSHA results of the Boore and Atkinson [37], Campbell and Bozorgnia [38] and Chiou and Youngs [39] GMPEs (conventional PSHA; Alternative C). The probabilistic site factors computed from Alternative A and Alternative B use Equation (1). The only difference between these two alternatives is the soil response model: it is site-specific in Alternative A whereas it is represented by the generic site models in (Alternative B; proposed method in this study). The hazard curve in Alternative B is the median of hazard curves computed from the SAB13, SS14, CB14 and CY14 site models. The ground-motion predictive models in Alternative $\mathrm{C}$ are originally used for $\mathrm{V}_{\mathrm{S} 30}=760 \mathrm{~m} / \mathrm{s}$ to compute generic rock USGS hazard maps for median spectral ordinates [22]. The same GMPEs are employed to compute the median hazard curve at the location of interest for $\mathrm{V}_{\mathrm{S} 30}=260 \mathrm{~m} / \mathrm{s}$. Hence, the probabilistic site factors computed in Alternative $\mathrm{C}$ follow the hazard-consistent site factor computation method [32].

The implemented methods consider the aleatory variability and epistemic uncertainty in site factors at different levels. Alternatives A and B account for the aleatory variability via the standard deviations of site-specific soil response model or generic soil amplification models. The aleatory variability is addressed by the standard deviations of ground-motion predictive models in Alternative C. The epistemic uncertainty is addressed by using multiple soil amplification functions and multiple GMPEs in Alternative B and Alternative C, respectively. Epistemic uncertainty is disregarded in Alternative A because it uses a single site-specific soil response model. These are already explained in the previous section.

Figures 6.c and 6.d show the complementary cumulative distributions of site amplifications for a 50 -year time interval by normalizing the hazard curves of $\mathrm{V}_{\mathrm{S} 30}=$ $260 \mathrm{~m} / \mathrm{s}$ with the USGS generic rock $\left(\mathrm{V}_{\mathrm{S} 30}=760 \mathrm{~m} / \mathrm{s}\right)$ hazard curve. The site amplifications computed from different alternatives having $90 \%$ and $98 \%$ nonexceedance probabilities (or $10 \%$ and $2 \%$ exceedance probabilities, respectively) can be read from the dashed lines. These site factors would correspond to 475-year and 2475year return periods if the earthquake occurrences are assumed to follow Poisson process. Note that the 475-year and 2475-year hazard levels are widely used in the engineering community to establish design- or assessment-based response spectra for a broad range of structural systems. Table 1 lists the site amplifications computed from all three 
alternatives: conventional PSHA probabilistic approach (Alternative C), proposed procedure that employs soil amplification models (Alternative B) and the origin of our proposed procedure [21] that considers site-specific soil response.

Table 1. Probabilistic site amplifications computed from three alternative approaches discussed in Figure 6

\begin{tabular}{|c|c|c|c|c|}
\hline & Return Period & Alternative C & Alternative B & Alternative A \\
\hline \multirow{2}{*}{$\mathrm{T}=0.2 \mathrm{~s}$} & $475 \mathrm{yrs}$ & 1.24 & 1.30 & 1.12 \\
\cline { 2 - 5 } & $2475 \mathrm{yrs}$ & 1.11 & 1.04 & 0.84 \\
\hline \multirow{2}{*}{$\mathrm{T}=1.0 \mathrm{~s}$} & $475 \mathrm{yrs}$ & 2.05 & 2.52 & 2.41 \\
\cline { 2 - 5 } & $2475 \mathrm{yrs}$ & 2.00 & 2.20 & 1.74 \\
\hline
\end{tabular}
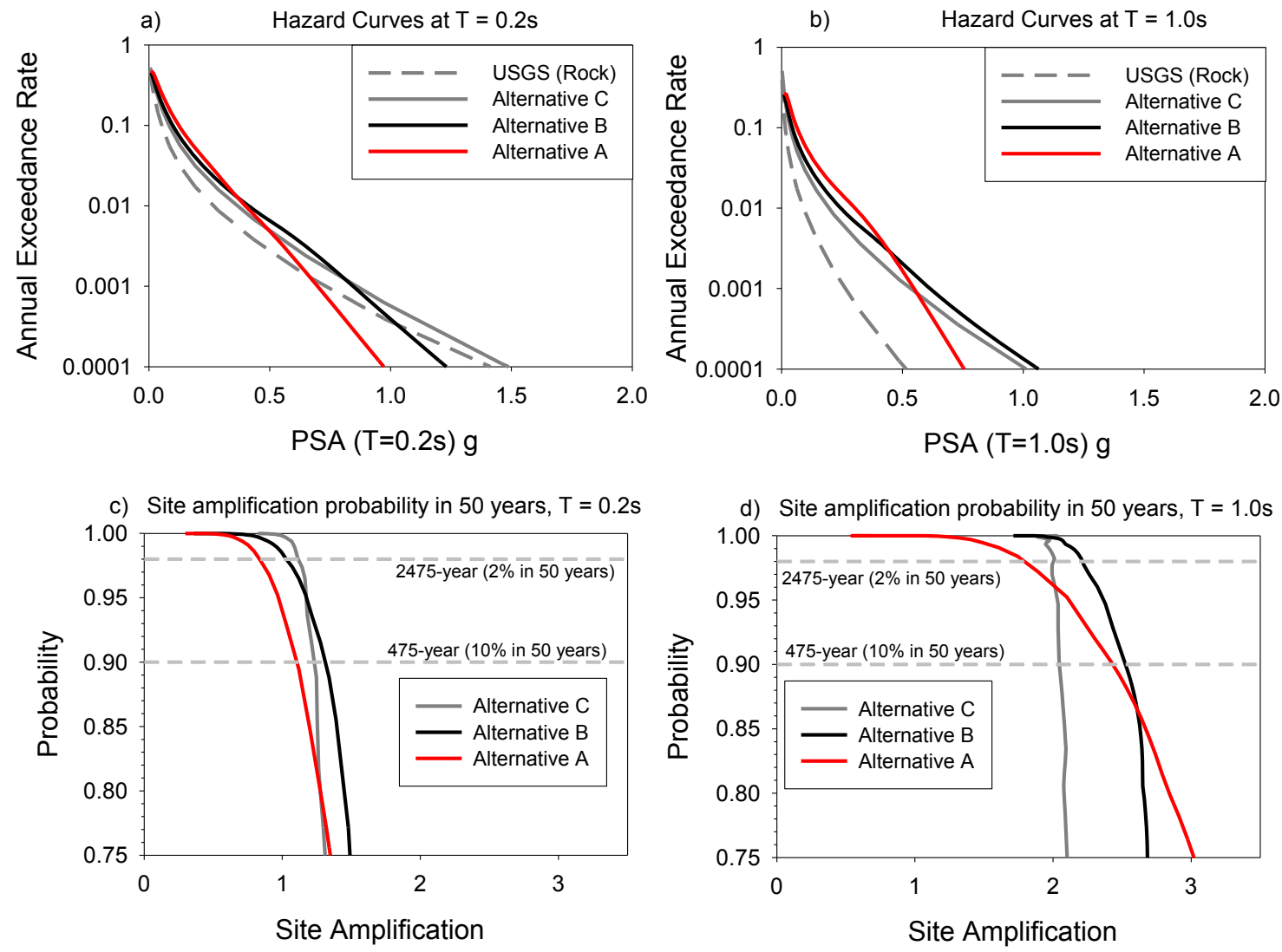

Fig. 6. Comparison of soil hazard curves for $V_{\mathrm{S} 30}=260 \mathrm{~m} / \mathrm{s}$ computed from alternative methods for (a) $\mathrm{T}=0.2 \mathrm{~s}$ and (b) $\mathrm{T}=1.0 \mathrm{~s}$ spectral ordinates. The corresponding site amplifications representing different non-exceedance probabilities at (c) $\mathrm{T}=0.2 \mathrm{~s}$ and (d) $\mathrm{T}=1.0 \mathrm{~s}$.

The observed differences in Figure 6 as well as Table 1 reveal the impact of alternative methods on the computed site amplifications. Alternatives B and C yield considerably different site amplifications at $\mathrm{T}=1.0 \mathrm{~s}$ for 475 -year return period (Figure 6.d). Besides, the differences between Alternatives $\mathrm{B}$ and $\mathrm{C}$ are more notable at lower non-exceedance probabilities (smaller return periods) for both short $(\mathrm{T}=0.2 \mathrm{~s})$ and $\mathrm{T}=$ 
1.0s spectral ordinates. The site amplifications computed from Alternative A generally follow a very different pattern with respect to those computed from Alternatives B and C. This is expected because the soil amplification model in Alternative A is developed from a site-specific soil response analysis. This last observation emphasizes the significance of soil amplification model in determining the site factors.

Figure 7 presents the implications of hazard-consistent site factors computed from Alternatives $\mathrm{B}$ and $\mathrm{C}$ on the idealized response spectrum. The spectra in Figure 7 are computed by adopting the formulations in the 2009 and 2015 editions of the NEHRP provisions. The panels in Figure 7 also display the idealized response spectra computed by direct use of site factors provided in the 2015 edition of the NEHRP provisions. The NEHRP site factors are based on the Seyhan and Stewart [17] study and are not developed to represent a specific exceedance (or non-exceedance) probability. The comparisons in Figure 7 suggest that the Alternatives B and C estimate different levels of spectral ordinates and the differences are more notable at smaller return periods and longer spectral ordinates, which is in parallel with the observations made from Figure 6. The NEHRP and conventional PSHA (Alternative C) spectra follow each other very closely, which holds true particularly for 2475-year return period (Figure 7.a). The similarity between the conventional PSHA and NEHRP spectra could be coincidental because the NEHRP provisions do not provide site factors for a specific $\mathrm{V}_{\mathrm{S} 30}$ value. The NEHRP site factors are rather representatives of a site class encompassing a range of $\mathrm{V}_{\mathrm{S} 30}$ values (which is NEHRP D, $180 \mathrm{~m} / \mathrm{s}<\mathrm{V}_{\mathrm{S} 30}<360 \mathrm{~m} / \mathrm{s}$, for this particular example). On the other hand, the conventional PSHA spectrum presented here is computed by normalizing the soil hazard curve of $\mathrm{V}_{\mathrm{S} 30}=260 \mathrm{~m} / \mathrm{s}$ with the corresponding reference rock hazard.
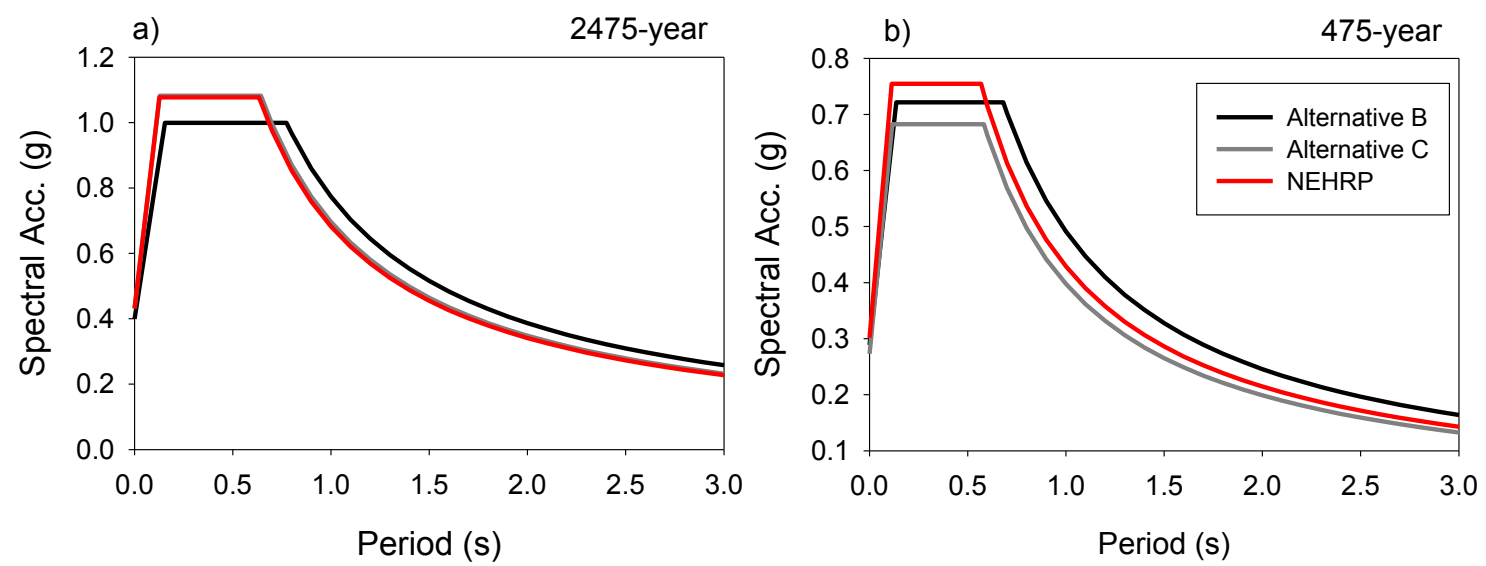

Fig. 7. Design spectrum envelopes at different return periods computed from alternative approaches for $\mathrm{V}_{\mathrm{S} 30}=260 \mathrm{~m} / \mathrm{s}$. 


\subsection{Extension of the proposed methodology to regional scale to compute hazard-consistent site factors}

The single-site case study shows that the exceedance (or non-exceedance) probabilities of site factors at different return periods can significantly change the soil amplification and the probabilistic approach can address this phenomenon in a technically defensible manner. To this end, the use of probabilistic site factors in seismic design codes would be more appropriate that requires their extension to a regional scale. This way, the variations in seismic hazard over a region would be more properly reflected on the soil amplification by the computed site factors. The implementation of proposed probabilistic site factor approach to a regional scale for a specific spectral period is itemized in the following.

1. Given a GMIM (e.g., spectral acceleration at $\mathrm{T}=1.0 \mathrm{~s}$ ) obtain the reference rock hazard curves at the centers of the grid cells spanning the entire region of interest (e.g., country).

2. Given a soil condition use Eq. (1) and obtain the hazard curves at the centers of the grid cells for the same GMIM. One can use a suite of empirical (or semiempirical) site models (e.g., SS14, SAB13, CB14, CY14, etc.) to account for the epistemic uncertainty in soil amplification. The site models can attain different weights in accordance with their model limitations (or other constraints important to the objectives in the project).

3. Given a pre-determined return period (e.g., 2475-year or 475-year return periods) normalize the weighted average of soil hazard curves obtained at step \#2 with the reference rock hazard curves at each grid cell. The normalized amplifications at the end of this process would be the site factors of the given soil condition and designated return period.

4. Collect the computed site factors and the corresponding reference rock GMIMs to develop the code-based site factor relationship. Repeat this step for the rest of the soil conditions as well as the other GMIMs of interest (e.g., PGA, spectral acceleration at $\mathrm{T}=0.2 \mathrm{~s}$, etc.) and return periods.

Apart from the use of multiple site functions, additional aspects in the computation of site factors can be taken into account in the above methodology. Firstly, the site classes can be represented by a suite of $\mathrm{V}_{\mathrm{S} 30}$ values together with a specific weighting strategy to 
obtain more refined site factors. This is similar to implementing the logic-tree approach [e.g., 40] and the resulting site factors can represent a distribution at the center of each cell. The analyst can use either the median $\left(50^{\text {th }}\right.$ percentile $)$ or another fractile of the site factor distribution. Secondly, the spatial variation of the GMIMs within a grid cell can be considered in the calculations since the current approach assumes that the GMIMs computed at the center of the grids are valid for the entire grid area. In reality, depending on the grid size, the lumped GMIM at the center may fail to represent the variation of ground motion for the entire cell [41]. Such sophistications may lead to more realistic probabilistic site factors at the expense of computational time. One can even employ sampling techniques (e.g., Monte Carlo simulations) to systematically address the variation of all critical components in the development of full-probabilistic site factors.

The proposed procedure is implemented to the regions selected from southern California and western Arizona (Figure 5). We use the SAB13, SS14, CB14 and CY14 site models and followed the presented procedure. We consider three NEHRP site classes (NEHRP C, D and E) and each site class is represented by five different $\mathrm{V}_{\mathrm{S} 30}$ values (NEHRP C: 360, 460, 560, 660 and 760m/s; NEHRP D: 180, 225, 270, 315 and 360m/s; NEHRP E: $120,135,150,165$ and $180 \mathrm{~m} / \mathrm{s}$ ). The reference rock condition is represented by $\mathrm{V}_{\mathrm{S} 30}=760 \mathrm{~m} / \mathrm{s}$. Equal weights and median fractile $\left(50^{\text {th }}\right.$ percentile $)$ are used in the calculations. Following Borcherdt [3], the site factors controlling the short- and longperiod spectral regions are computed by averaging the median site factors computed for $\mathrm{T}$ $=0.1 \mathrm{~s}, \mathrm{~T}=0.2 \mathrm{~s}$ and $\mathrm{T}=0.5 \mathrm{~s}$ (short-period site factors) and $\mathrm{T}=0.5 \mathrm{~s}, 1.0 \mathrm{~s}$ and $2.0 \mathrm{~s}(\mathrm{~T}=1 \mathrm{~s}$ site factors). The target return periods are chosen as 475-year and 2475-year in the computations. Figure 8 presents the probabilistic site factors computed for southern California (designated by CA), western Arizona (designated by AZ) and their combination (blue solid line). The panels in this figure compare the computed site factors with those of NEHRP (red solid line) and EC8 (black dashed and solid lines). The EC8 site classifications of B, C and D correspond to NEHRP C, D and E site classes, respectively.

The site factors computed from the proposed procedure indicate a clear influence of regional seismicity (low-to-moderate seismicity vs. moderate-to-high seismicity) and annual exceedance rate (475-year vs. 2475-year return period). This observation may have different implications for seismic design codes as more realistic site factors can be provided to the engineers depending on the target hazard level as well as the seismic activity at the region of interest. The site factors in the western Arizona are larger than the ones computed for the southern California for NEHRP E and D site classes (EC8 D and C 
site classes, respectively). Relatively high spectral amplitudes in California that invoke nonlinear soil behavior is believed to be the main reason behind this observation because the differences in the computed site factors between $\mathrm{CA}$ and $\mathrm{AZ}$ are rather insignificant for NEHRP C site class where the influence of soil nonlinearity would be rather limited due to the stiff soil conditions for this site class.

The full-probabilistic site factors and those of NEHRP provisions follow the same trends albeit comparable differences exist for $\mathrm{T}=1.0 \mathrm{~s}$ NEHRP D site class as well as for short-period NEHRP E and D site classes when reference rock $\left(\mathrm{V}_{\mathrm{S} 30}=760 \mathrm{~m} / \mathrm{s}\right)$ spectral amplitudes attain intermediate-to-low values. The sources of observed differences may be two folded: (1) the different approaches in the computation of site factors by Borcherdt [3] and Seyhan and Stewart [17] and (2) differences in the exceedance probabilities of the computed site factors; our site factors pose the same exceedance probability for the entire reference rock spectral amplitudes whereas the NEHRP site factors exhibit a non-uniform exceedance probability as discussed in Figure 4. The patterns followed by EC8 site factors are generally different than the probabilistic and NEHRP site factors. The EC8 site factors are insensitive to the variations in reference rock spectral ordinates and their period-dependent variation is poorly constrained since the spectrum envelope is only scaled by PGA. Besides EC8 site factors overlook nonlinear soil behavior and they do not represent a homogenous exceedance probability, which is also the case for NEHRP site factors (Figure 4). These weaknesses result in the observed differences between EC8 and other site factors that are emphasized throughout the text in the paper. 

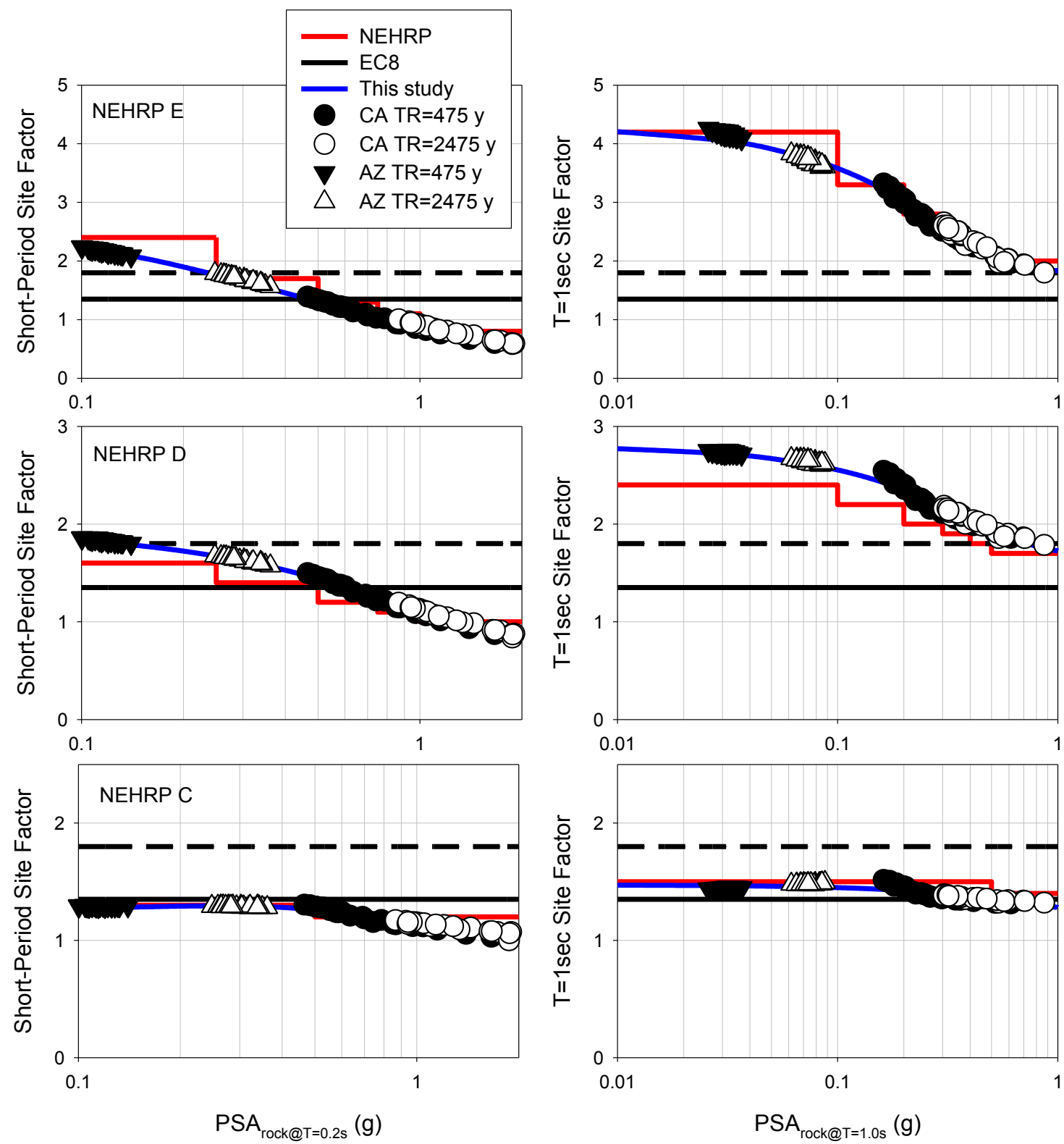

Fig. 8. Comparisons of short- and $T=1.0 \mathrm{~s}$ site amplifications for updated NEHRP (presented by SS14), EC8 and the proposed probabilistic site factor methodology.

\section{Conclusions}

We present a probabilistic procedure to compute hazard-consistent site factors for seismic design codes. Before introducing the procedure our studies on the site amplifications computed from a suite of earthquake scenarios (triplets) indicate that the seismic activity is important in the variation of site factors and its consideration would yield more realistic site factors. Besides, the triplet analysis also show that the site factors in Eurocode 8 and NEHRP do not provide a uniform probability for a given seismic demand level, which can affect the computation of a fully consistent design spectrum for 
a certain probability of exceedance. In other words, the use of site factors having exceedance probabilities different than those of reference rock spectral ordinates given for a predefined annual exceedance rate (via seismic hazard maps) may result in a design spectrum that fails to represent the actual hazard level under the target site class. This is not ideal for probabilistic performance based seismic design since the exceedance probabilities of earthquake demand is related to the damage state probabilities to verify the structural performance for a given probability.

Apart from above observations the triplet analysis pointed out other shortcomings about Eurocode 8 site factors: improper representation of nonlinear soil response, single site factors for a given site class regardless of variations in reference rock spectral amplitudes and poor period-dependent variation. The observations imply significant deviations from the site factors computed from the site response models as well as those provided in the NEHRP guidelines.

As a surrogate to the non-uniform exceedance probability of code-based site factors, the presented probabilistic site factor procedure uses the convolution method described in Bazzuro and Cornell [21] that estimates the annual exceedance probability of a spectral ordinate for a given threshold level under a specific site condition. We use several site models (e.g., SAB13) to describe the probability of site amplification exceeding a threshold value conditioned on a reference rock ground-motion amplitude $\left(\mathrm{GMIM}_{\text {rock}}\right)$. This probability is convolved with the occurrence probability of GMIM $_{\text {rock }}$ over the entire range of GMIM $_{\text {rock }}$ values to obtain the annual exceedance of the spectral ordinate of interest for the designated site condition. The annual occurrence probability of the GMIM $_{\text {rock }}$ is the derivative of its hazard curve. When the computed spectral amplitude is normalized by the reference rock ground-motion amplitude at the same annual exceedance probability, the resulting site factor would exhibit the same probability as well. For demonstration purposes, this methodology is implemented over a region by mesh gridding the entire area into cells to compute the site factor at each cell for the same annual exceedance probability for a given site condition. The model uncertainty in the definition of soil response (i.e., site models) or a more refined description of site class with a set of $\mathrm{V}_{\mathrm{S} 30}$ values can be addressed by implementing a weighting strategy similar to the one in the logic-tree concept. The resulting site factors describe a probability distribution and a fractile (e.g., median) of this probability distribution can be set as the site factor. Since the proposed approach makes use of reference rock site hazard, the computed site factors are sensitive to the variations in the seismic activity of the subject region. 


\section{Acknowledgments}

The initial phase of this study is realized under the Seismic Hazard Harmonization in Europe (SHARE) project that is funded by EU's $7^{\text {th }}$ Framework Programme for Research (FP7). The initial phase of the study was also conducted during M.A. Sandikkaya's doctoral studies and The Scientific and Technical Research Council of Turkey (TUBITAK) provided a fellowship to M.A. Sandıkkaya during his doctoral studies in France. This paper is one of the products of his follow-up studies as the faculty member of Hacettepe University. The authors express their sincere gratitude to two anonymous reviewers. Their comments led to many improvements in the paper. Finally, we thank Prof. Pitilakis, the guest editor of this special issue, who smoothly coordinated the review process and also gave constructive comments for the improvements in the technical essence of the paper.

\section{References}

[1] Borcherdt, Roger D. "Effects of local geology on ground motion near San Francisco Bay." Bulletin of the Seismological Society of America 60.1 (1970): 29-61.

[2] Seed, H. Bolton, Celso Ugas, and John Lysmer. "Site-dependent spectra for earthquake-resistant design." Bulletin of the Seismological Society of America 66.1 (1976): 221-243.

[3] Borcherdt, Roger D. "Estimates of site-dependent response spectra for design (methodology and justification)." Earthquake spectra 10.4 (1994): 617-653.

[4] Dobry, R., et al. "New site coefficients and site classification system used in recent building seismic code provisions." Earthquake spectra 16.1 (2000): 41-67.

[5] Rodriguez-Marek, Adrian, Jonathan D. Bray, and Norman A. Abrahamson. "An empirical geotechnical seismic site response procedure." Earthquake Spectra 17.1 (2001): 65-87.

[6] Rey, Julien, Ezio Faccioli, and Julian J. Bommer. "Derivation of design soil coefficients (S) and response spectral shapes for Eurocode 8 using the European StrongMotion Database." Journal of seismology 6.4 (2002): 547-555.

[7] Stewart, Jonathan P., Andrew H. Liu, and Yoojoong Choi. "Amplification factors for spectral acceleration in tectonically active regions." Bulletin of the Seismological Society of America 93.1 (2003): 332-352. 
[8] Pitilakis, Kyriazis, Evi Riga, and Anastasios Anastasiadis. "New code site classification, amplification factors and normalized response spectra based on a worldwide ground-motion database." Bulletin of Earthquake Engineering 11.4 (2013): 925-966.

[9] BSSC, Building Seismic Safety Council. NEHRP Recommended Seismic Provisions for New Buildings and Other Structures: Part 1, Provisions. Federal Emergency Management Agency (P-750), Washington D.C., 2009

[10] CEN, Comité Européen de Normalisation. Eurocode 8, Design of structures for earthquake resistance-part 1: General rules, seismic actions and rules for buildings. European Standard NF EN 1998-1, Brussels., 2004.

[11] Pitilakis, Kyriazis, Evi Riga, and Anastasios Anastasiadis. "Design spectra and amplification factors for Eurocode 8." Bulletin of Earthquake Engineering (2012): 1-24.

[12] Yenier, E., M. A. Sand1kkaya, and S. Akkar. "Report on the fundamental features of the extended strong motion databank prepared for the SHARE project." Deliverable 4 (2010): 44 .

[13] Sandıkkaya, M. Abdullah, Sinan Akkar, and Pierre-Yves Bard. "A nonlinear siteamplification model for the next pan-European ground-motion prediction equations." Bulletin of the Seismological Society of America 103.1 (2013): 19-32.

[14] Huang, Yin-Nan, Andrew S. Whittaker, and Nicolas Luco. "NEHRP site amplification factors and the NGA relationships." Earthquake Spectra 26.2 (2010): 583593.

[15] Borcherdt, Roger D. "Implications of next generation attenuation ground motion prediction equations for site coefficients used in earthquake resistant design." Earthquake Engineering \& Structural Dynamics 43.9 (2014): 1343-1360.

[16] Power, Maurice, et al. "An overview of the NGA project." Earthquake spectra 24.1 (2008): 3-21.

[17] Seyhan, Emel, and Jonathan P. Stewart. "Semi-empirical nonlinear site amplification from NGA-West2 data and simulations." Earthquake Spectra 30.3 (2014): 1241-1256.

[18] Bozorgnia, Yousef, et al. "NGA-West2 research project." Earthquake Spectra 30.3 (2014): 973-987.

[19] BSSC, Building Seismic Safety Council. NEHRP Recommended Seismic Provisions for New Buildings and Other Structures, Washington D.C., 2015

[20] ASCE, American Society of Civil Engineers. Minimum Design Loads for Buildings and Other Structures, ASCE/SEI 7-16., Reston, Virginia, (2016). 
[21] Bazzurro, Paolo, and C. Allin Cornell. "Nonlinear soil-site effects in probabilistic seismic-hazard analysis." Bulletin of the Seismological Society of America 94.6 (2004): 2110-2123.

[22] Petersen, Mark D., et al. Documentation for the 2008 update of the United States national seismic hazard maps. No. 2008-1128. Geological Survey (US), 2008.

[23] Giardini, D., Woessner, J., et al.., 2013. Seismic Hazard Harmonization in Europe (SHARE): Online Data Resource, doi:10.12686/SED-00000001-SHARE.

[24] Petersen, M.D., Moschetti, M.P., Powers, P.M., Mueller, C.S., Haller, K.M., Frankel, A.D., Zeng, Yuehua, Rezaeian, Sanaz, Harmsen, S.C., Boyd, O.S., Field, Ned, Chen, Rui, Rukstales, K.S., Luco, Nico, Wheeler, R.L., Williams, R.A., and Olsen, A.H., 2014, Documentation for the 2014 update of the United States national seismic hazard maps: U.S. Geological Survey Open-File Report 2014-1091, 243 p., https://dx.doi.org/10.3133/ofr20141091.

[25] Abrahamson, N. A., and Walter J. Silva. "Empirical response spectral attenuation relations for shallow crustal earthquakes." Seismological research letters 68.1 (1997): 94127.

[26] Choi, Yoojoong, and Jonathan P. Stewart. "Nonlinear site amplification as function of 30 m shear wave velocity." Earthquake Spectra 21.1 (2005): 1-30.

[27] Walling, Melanie, Walter Silva, and Norman Abrahamson. "Nonlinear site amplification factors for constraining the NGA models." Earthquake Spectra 24.1 (2008): 243-255.

[28] Kamai, Ronnie, Norman A. Abrahamson, and Walter J. Silva. "Nonlinear horizontal site amplification for constraining the NGA-West2 GMPEs." Earthquake Spectra 30.3 (2014): 1223-1240.

[29] Chiou, Brian S-J., and Robert R. Youngs. "Update of the Chiou and Youngs NGA model for the average horizontal component of peak ground motion and response spectra." Earthquake Spectra 30.3 (2014): 1117-1153.

[30] Boore, David M., et al. "NGA-West2 equations for predicting PGA, PGV, and 5\% damped PSA for shallow crustal earthquakes." Earthquake Spectra 30.3 (2014): 10571085.

[31] Campbell, Kenneth W., and Yousef Bozorgnia. "NGA-West2 ground motion model for the average horizontal components of PGA, PGV, and 5\% damped linear acceleration response spectra." Earthquake Spectra 30.3 (2014): 1087-1115. 
[32] Akkar, S., M. A. Sandıkkaya, and J. J. Bommer. "Empirical ground-motion models for point-and extended-source crustal earthquake scenarios in Europe and the Middle East." Bulletin of earthquake engineering 12.1 (2014): 359-387.

[33] Goulet, Christine A., and Jonathan P. Stewart. "Pitfalls of deterministic application of nonlinear site factors in probabilistic assessment of ground motions." Earthquake Spectra 25.3 (2009): 541-555.

[34] Papaspiliou, Myrto, Stavroula Kontoe, and Julian J. Bommer. "An exploration of incorporating site response into PSHA-part II: Sensitivity of hazard estimates to site response approaches." Soil Dynamics and Earthquake Engineering 42 (2012): 316-330.

[35] Norman Abrahamson, Gail Atkinson, David Boore, Yousef Bozorgnia, Kenneth Campbell, Brian Chiou, I. M. Idriss, Walter Silva, and Robert Youngs (2008) Comparisons of the NGA Ground-Motion Relations. Earthquake Spectra: February 2008, Vol. 24, No. 1, pp. 45-66.

[36] Nick Gregor, Norman A. Abrahamson, Gail M. Atkinson, David M. Boore, Yousef Bozorgnia, Kenneth W. Campbell, Brian S.-J. Chiou, I. M. Idriss, Ronnie Kamai, Emel Seyhan, Walter Silva, Jonathan P. Stewart, and Robert Youngs (2014) Comparison of NGA-West2 GMPEs. Earthquake Spectra: August 2014, Vol. 30, No. 3, pp. 1179-1197.

[37] Boore, David M., and Gail M. Atkinson. "Ground-motion prediction equations for the average horizontal component of PGA, PGV, and 5\%-damped PSA at spectral periods between $0.01 \mathrm{~s}$ and 10.0 s." Earthquake Spectra 24.1 (2008): 99-138.

[28] Campbell, Kenneth W., and Yousef Bozorgnia. "NGA ground motion model for the geometric mean horizontal component of PGA, PGV, PGD and 5\% damped linear elastic response spectra for periods ranging from 0.01 to 10 s." Earthquake Spectra 24.1 (2008): 139-171.

[39] Chiou, BrianS-J., and Robert R. Youngs. "An NGA model for the average horizontal component of peak ground motion and response spectra." Earthquake Spectra 24.1 (2008): 173-215.

[40] Delavaud E, Cotton F, Akkar S, Scherbaum F, Danciu L, Beauval C, Drouet S, Douglas J, Basili R, Sandikkaya A, Segou M, Faccioli E, Theodoulidis N (2012) Toward a ground-motion logic tree for probabilistic seismic hazard assessment in Europe. $\mathrm{J}$ Seismol 16(3):451-473

[41] Stafford, Peter J. "Evaluation of structural performance in the immediate aftermath of an earthquake: a case study of the 2011 Christchurch earthquake." International Journal of Forensic Engineering 1.1 (2012): 58-77. 
